\title{
CD-expressing Bifidobacterium APS001F
}

National Cancer Institute

\section{Source}

National Cancer Institute. CD-expressing Bifidobacterium APSO01F. NCI Thesaurus. Code C101367.

A recombinant anaerobic bacterium, Bifidobacterium longum, encoding the cytosine deaminase (CD) gene with potential antineoplastic adjuvant activity. Upon injection, the CD-expressing bifidobacterium preferentially localizes and grows in the hypoxic environment of the tumor and expresses CD, an enzyme that catalyzes the intracellular conversion of the prodrug flucytosine (5-FC) into the antineoplastic agent 5-fluorouracil (5-FU). Upon administration of 5-FC, and subsequent localized conversion into 5-FU and its cytotoxic active metabolites, the tumor is specifically exposed to cytotoxic agents while the exposure to normal tissues is minimal. 